\title{
Crude extract of Wintersweet (Chimonanthus praecox) as Corrosion Inhibitor for Mild Steel in Hydrochloric Acid
}

\author{
Kun Cao*, Leilie Yu, Lan Wang, Xian He \\ Department of Chemistry \& Chemical Engineering, Neijiang Normal University, Neijiang, Sichuan, \\ 641112, PR China \\ *E-mail: kevin_cao0811@126.com.
}

doi: $10.20964 / 2021.05 .29$

Received: 2 December 2020 / Accepted: 20 February 2021 / Published: 31 March 2021

\begin{abstract}
Anticorrosion properties of the wintersweet leaf crude extract (WSLCE) were tested in relationship to the mild steel corrosion in $1 \mathrm{M} \mathrm{HCl}$ using gravimetric analysis as well as potentiodynamic polarization and electrochemical impedance tests. The anticorrosive efficiency of WSLCE increased from 76.4\% to $91.5 \%$ as its content in the solution was increased from 0.1 to $1.0 \mathrm{~g} / \mathrm{L}$, respectively. WSLCE behaved as a mixed-type cathodic inhibitor. Extensive characterization of the corrosion products (by SEM, AFM, FTIR, and XPS) showed that WSLCE was adsorbed by the steel surface. Thin WSLCE layer formed on the mild steel surface prevented electron exchange between the steel and $\mathrm{HCl}$, impeding corrosion.
\end{abstract}

Keywords: anticorrosion; leaf crude extract; inhibitor; adsorption; electrochemical methods

\section{FULL TEXT}

(C) 2021 The Authors. Published by ESG (www.electrochemsci.org). This article is an open access article distributed under the terms and conditions of the Creative Commons Attribution license (http://creativecommons.org/licenses/by/4.0/). 